\title{
The Design and Implementation of Real Time Warning Module of Bank Financial Accounting Supervision System
}

\author{
Jian Zhang \\ \{zhangjian@sicau.edu.cn\} \\ College of economics, Sichuan Agricultural University Chengdu 611130, China
}

\begin{abstract}
With the expansion of the banking and electronic construction, the contradiction between the bank's financial information security and business development have become increasingly prominent, on the one hand, the bank to provide quality and efficient financial services products, on the other hand, the bank must guarantee the financial information security, although the commercial banks have applied a network firewall, and VPN electronic certificates and other security products to protect their information security, but this kind of product can effectively prevent the illegal intrusion from the outside of the bank, and the bank's internal financial crime has little effect on, mainly because the internal staff understand the information system of the bank, to their own illegal purposes by system or system vulnerabilities, so from the internal bank financial security has become a serious problem of commercial banks. Agricultural Bank of China developed a set of security software products - accounting supervision system (accounting risk monitoring system is introduced in this paper, referred to as arms). The system is through real-time screening of transaction data, in accordance with the rules of the setting of the parameters, the idiosyncratic risk adequately identify and inherent laws of logic judgment of risk monitoring and early warning platform; is auxiliary routine supervision, standardize management business process, intelligent information systems.
\end{abstract}

Keywords: Bank finance and accounting; supervision system; real time warning; system design.

\section{Introduction}

The traditional accounting supervision, focusing on the compliance of the business operation, the account level table must be the basic requirements. With the extensive application of the financial products innovation and electronic, to accounting brought profound changes, to improve efficiency at the same time is also the breeding ground for the accounting risk, due to the restriction of various elements of the, to risk control is also a lack of effective method. Therefore, to the accounting supervision brought new challenges. Current accounting supervision, the more the manual inspection method, check the contents of the partial to the work quality and various accounts, tables, check book, lack of the front desk business risk control and trend analysis, failed to do so true have a definite object in view [1]. In the financial risk control, and depends on the inherent rule of the computer, and the 
computer processing business process of human-computer interaction, the initiative of the people is always greater than the computer and business rules master in the hands of the operator, in actual operation, the lack of effective constraints and safety monitoring, there are in fact of operational risk and moral risk. If in the integrated business system implementation or increase safety related control, it will make comprehensive business system in the fast and accurate processing of the transaction is completed, also need according to each transaction to the relevant monitoring rules judgment; if the monitoring rules and historical trading related, there is also a need of historical trading retrieval judgment. This not only increases the time cost of processing the single transaction, but also increases the operation load of the integrated business system, and it has a great use for its performance, thus increasing the load pressure of the integrated business system.

\section{Overall Design}

This system is for the merchants bank risk early warning of financial information monitoring system, its main purpose is safe, reliable, convenient for the user to operate the transaction account monitoring, covering the comprehensive business of banks and other financial institutions of all financial aspects, to the merchants bank financial information risk pre sound really realize the informatization of financial risk business. The system to support the bank account for the financial services for monitoring and early warning. System can adapt to the flexible and convenient deployment, can fully meet the needs of the future management of the bank risk.

Because of the construction of the risk supervision system, it involves the information of operation process management, the integration and sharing of information resources, the processing of decision-making information, the analysis of the effect of management and other routine analysis and information release. Therefore, the risk supervision system is not a simple business, independent business management system, it involves the risk of the whole process of management of various types of business, the management of many. The risk supervision system project needs to have good human resources, development system, network environment, the target machine and the best support software and application software. Through the analysis of the risk supervision and management of commercial banks, the risk management process and operation process of information construction is almost blank, the risk management method is backward, the information is poor. In the process of risk management, there are a lot of operational links, each link will have the information generated, but also need other aspects of information support. At present, commercial bank risk supervision operation is not supported by the effective operation system, various procedures are independent of each other, information gap, the managers to spend more time and experience of operating records manual records and related data processing, not convenient and efficient access to effective decision-making information, statistical analysis is very difficult to work, there is no established effective risk control system [2]. 


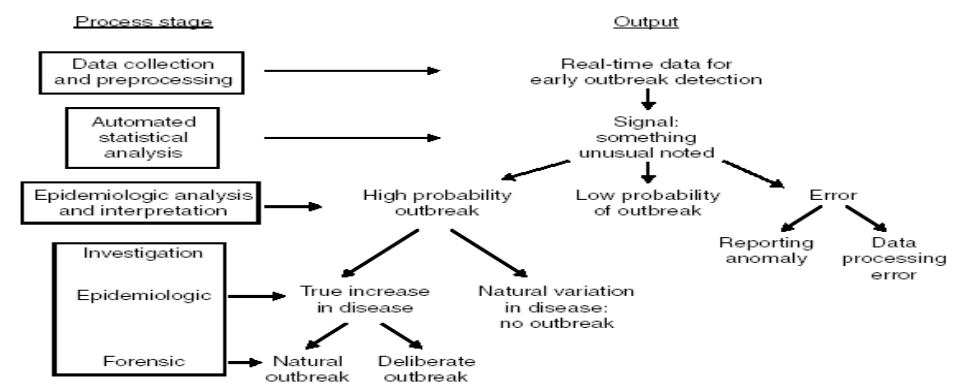

Fig. 1. System decision risk warning sketch map

\subsection{System Architecture Design}

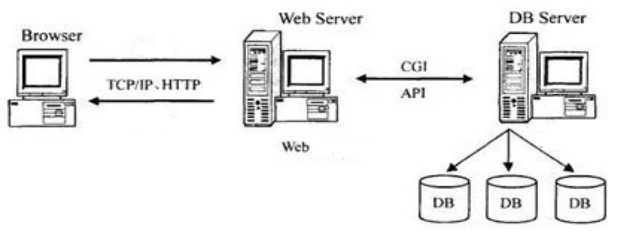

Fig. 2. Schematic Diagram of System Architecture

Overall framework of the system construction adhere to "demand-oriented, to apply and promote development" policy, building a unified management, unified planning, step by step implementation, interoperability, resource sharing of electronic information system. Based on the coverage of financial risk monitoring and early warning management of all relevant business processes, the union business processing, information management and decision analysis in various advanced solutions. Such management center can have an efficient processing, safe and reliable accounting electronic center for merchants bank financial center, and in the unified management of the financial risk early warning and monitoring data, accurate application provides a strong guarantee, make various business personnel business comes in response to timely and, to make a judgment, in future expansion of business for the new function of the system increased to provide more effective basis. Top down system design, the client server architecture and object oriented design method as shown in figure, divides the system into various functional areas, each functional area and then refine the various functions, detailed analysis of the operation of the function, functional area between the interface relationship and business exchanges, each functional area division of implementation and operation combination, achieve the goal of overall function [3].

\subsection{System Function and Process Design}

Early warning information display and processing of the main structure of the design process and the introduction of basic information, there are mainly early warning information to show, early warning information display, early warning, etc.. Early warning information display: early warning information to show the basic attribute definition, show the definition of the basic information such as name, permissions, view the relationship between the content and the personnel; definitions show data sources, data definition show the corresponding data 
source, table; definition show field and definition to show the field, as well as related flexion; definitions show definition defined show include list, pie charts, bar charts, line figure. Early warning information display: early warning information queries, according to the conditions of the query pre for information; pre surprised letter always show, according to the definition of warning show and display warning information; pre shock derived information, the corresponding pre praise system to a format; pre breeding information print, print warning letter en. Warning: setting warning sign processing, to pre shock letter for confirmation; fill out pre shock information processing records, fill in the warning letter total processing table; pre shock times the total processing records to print, print pre breeding information processing table; pre for information processing records table view, pre breeding information query processing table; pre breeding information processing records statistics, statistical early warning information processing [4].

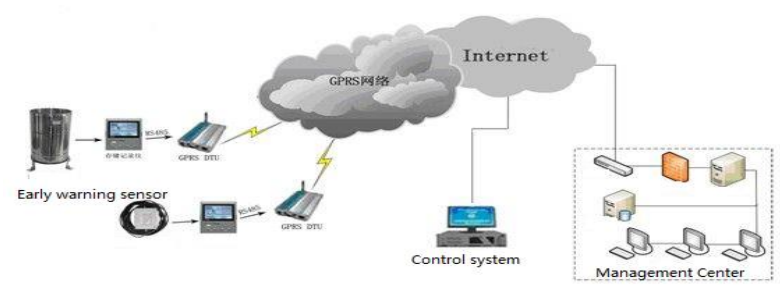

Fig. 3. Schematic diagram of system data transmission

\section{System Implementation}

In order to achieve effective warning business needs of various users, and truly become the bank supervision afterwards, internal management reform is a powerful enabler, system from the beginning to the end of life cycle management, starting from the definition of the model, through the flexible configuration for the user to build a personalized risk early warning system; through the acquisition of real-time transaction data, combined to achieve the establishment of monitoring and early warning model, to control the risk is happening, implementation supervision; rich warning system database construction based on multiple data sources, extracted from the effective information comprehensive analysis, formed and afterwards supervision and audit of the. In the early warning information processing, provides a powerful query, history tracing function and with the early warning information is sent a variety of early warning information sent to the relevant personnel, establish a convenient, comprehensive, timely and efficient process for early warning information processing, eventually establish a risk model, risk analysis automation, the real-time "advanced system of risk prevention. The definition of early warning model, the generation of information, processing, verification, storage, inspection can be completed in the system [5].

In accordance with the needs of users of scheme design and all kinds of data interface design, information of data capture, output method of customization; in the premise that makes sure the user convenient, as far as possible the use of the user interface is simple and easy operation; customize pre blurring of vision model according to the different requirements of early warning; at the same time in the system can be customized extends the different expansion interface; in other parts of its business reservation interface, considered in does not 
change the premise of other functions can be a different business model to join; while taking advantage of the existing communication methods, design risk monitoring and early warning system of real-time programs. Early warning business model can be standardized, can be released by the company's early warning model package automatically updated. Companies regularly publish early warning model package, on important business model package will be released in a timely manner, the user can according to their own needs update the business model, business model update and release function so that a bank share the management experience of other specialized banks quickly.

\section{Conclusion}

The in of bank risk monitoring and early warning system relevant background and significance of the general introduction, also on demand content were detailed analysis, according to the design goal of bank risk early warning and monitoring, performance requirements, according to the bank's overall business of planning analysis, again according to the plan a detailed description of the system design of the business system model of network security needs. In the overall design of the system, the overall structure of the system and the data information are analyzed, using the semantic tree to describe the system's functional design and the UML modeling of the supervision and early warning management. Bank risk supervision system to achieve specific pre sting implementation. Finally, the test and application of the system are carried out.

\section{References}

[1] Wen Yue Chun, Fan Wei. Construction of supervision system under the trend of financial integrated operation in China. Journal of Shanghai Finance University. No. 02. (2013)

[2] Shen Yue, Zhang Zhen. Establishment of China financial security early warning index system. Journal of Shanxi University of Finance and Economics. No. 10. (2012)

[3] Chen Xiaohui, Wu Yingyu. Dynamic control system of operational risk of commercial banks and Its Optimization Research. investment research. No. 10. (2015)

[4] Cheng Junshan, Qiu Xiao Cheng. The risk management of domestic and foreign banks in the gap between the. and Its Enlightenment of agricultural development and finance, No. 11. (2014)

[5] Yuan Xiaoping, Liu Changguo, Qin Lei. Study on risk early warning index system of state owned commercial banks. Shopping mall modernization. No. 14. (2011) 